\title{
THE HYPOGLYCAEMIC EFFECT OF OLEANONIC ACID ISOLATED FROM PILEA ELIZABETHAE IN
} A RAT MODEL

\author{
RUBY ALEXANDER-LINDO1, COLEEN SALMON1, DONOVAN MCGROWDER² \\ ${ }^{1}$ Department of Basic Medical Sciences, Faculty of Medical Sciences, the University of the West Indies, Kingston 7, Jamaica, West Indies, \\ ${ }^{2}$ Department of Pathology, Faculty of Medical Sciences, the University of the West Indies, Kingston 7, Jamaica, West Indies \\ Email: lisa.lindo@uwimona.edu.jm
}

Received: 23 Aug 2017, Revised and Accepted: 13 Oct 2017

\begin{abstract}
Objective: The objective of this study is to isolate and identify the chief hypoglycaemic component of Pilea elizabethae

Methods: The chief hypoglycaemic component of Pilea elizabethae was isolated and identified. The bio-directed purification of the chief hypoglycaemic agents contained in Pilea elizabethae followed a sequence of steps alternating oral glucose tolerance test (OGTT) bioassay and chromatographic methods. The ethyl acetate crude extract which was most hypoglycaemic in activity was flash chromatographed on silica gel using a gradient hexane-ethyl acetate solvent system of increasing polarity. Elucidation of the chemical structures of R-E2Gii was determined using NMR and FT-IR spectroscopy, melting point determination and comparison with the literature. The Pilea elizabethae extracts were tested for hypoglycaemic activity in Sprague-Dawley albino rats using the oral glucose tolerance test (OGTT) method. Isolated hypoglycaemic compounds obtained after bio-directed purification were identified through nuclear magnetic resonance (NMR) spectroscopy and infra-red (IR) spectroscopy.

Results: Bio-directed purification of Pilea elizabethae extracts yielded a hypoglycemic principle that were coded R-E2Gii. By comparison of its NMR chemical shift values and physical properties with literature values, R-E2Gii found to be the triterpenoid oleanonic acid [ $\mathrm{C}_{30} \mathrm{H}_{40} \mathrm{O}_{3} ; \mathrm{M}$. W=124]. The isolate R-E2Gii demonstrated significant hypoglycaemic activity. When administered intravenously, values were as low as $4.87 \pm 0.09 \mathrm{mmol} / \mathrm{l}$ thirty minutes post-load compared with $5.63 \pm 0.19 \mathrm{mmol} / \mathrm{l}$ for the control $(\mathrm{p}<0.006)$. An increase in dosage up to $10 \mathrm{mg} / \mathrm{kg}$ body weight amplified the post-prandial hypoglycaemic effect of R-E2Gii. Comparison of the hypoglycaemic effect of R-E2Gii with glibenclamide showed that the isolate was only mildly effective in reducing post-prandial hyperglycaemia. Hexane-ethyl acetate extracts from Pilea elizabethae was found to possess antihyperglycaemic activity on OGTT.
\end{abstract}

Conclusion: Bio-directed purification of the hexane-ethyl acetate extracts and using nuclear magnetic resonance (NMR) spectroscopy and infra-red (IR) spectroscopy revealed oleanonic acid, that may be responsible for the anti-hyperglycemic properties of this extract.

Keywords: Pilea elizabethae, Diabetes mellitus, Oleanonic acid, Hypoglycaemia

(c) 2017 The Authors. Published by Innovare Academic Sciences Pvt Ltd. This is an open access article under the CC BY license (http://creativecommons.org/licenses/by/4.0/) DOI: http://dx.doi.org/10.22159/ijcpr.2017v9i6.23431

\section{INTRODUCTION}

Normal glucose tolerance is mainly a function of the interplay between endocrine pancreatic function, which controls insulin release, and insulin sensitivity of muscle, liver, and adipose tissue. The American Diabetes Association (ADA) defines diabetes mellitus as a group of metabolic diseases characterized by hyperglycaemia resulting from defects in insulin secretion, insulin action or both [1]. The vast majority of cases fall into two broad etiopathogenetic categories. In type 1 diabetes mellitus there is an absolute deficiency of insulin secretion which results from autoimmune destruction of the cells of the pancreas. In the other much more prevalent category termed type 2 diabetes mellitus there is a combination of resistance to insulin action and inadequate compensatory insulin secretory response. This form of diabetes mellitus affects $90-95 \%$ of diabetic patients [1].

Despite numerous preventive strategies and armouries of medication, the prevalence of diabetes mellitus has increased over the last decade. Excess mortality attributable to diabetes mellitus has been estimated to account for $6-27 \%$ of the deaths globally in people aged 35-64 y in 2000 [2]. In addition, type 2 diabetes mellitus is also a significant cause of premature mortality and morbidity related to cardiovascular disease, blindness, kidney and nerve disease and amputations [3]. Globally it was estimated that diabetes mellitus accounted for $12 \%$ of health expenditures in 2010 , or at least $\$ 376$ billion, with a projection of $\$ 490$ billion by 2030 [4]. These estimates make a compelling case for the furtherance of research efforts aimed at finding more effective modalities to prevent and treat this disease. In the interim, an increasing number of people are turning to alternative therapies $[5,6]$ that include herbal remedies. Herbs have been used for food ingredients and for medicinal purposes for centuries. In fact, the World Health Organization estimated that approximately $80 \%$ of the earth's inhabitants rely on traditional medicine for their primary health care needs, and most of this therapy involves the use of plant extracts and their active components [7]. Keeping in perspective that many Western Drugs have their origin in a plant extract, researchers continue to explore various herbs that possess a hypoglycaemic effect for the next cutting-edge solution to the dilemma of effective diabetes prevention and management. Many of these herbs contain potent antioxidant compounds that are believed to provide significant protection against diabetes mellitus and many other chronic diseases [5].

This study focuses on Pilea elizabethae which is believed to be useful in the treatment of diabetes mellitus in Jamaican folklore. Scientific data on Pilea sp. is limited and in fact, this is the first study which validates the hypoglycaemic activity of this indigenous Jamaican plant. Notwithstanding, there are a few recent reports which may serve to corroborate the anti-diabetic, anti-hyperlipidemic, antioxidant, antimicrobial and radio-protective potential of bioactive secondary metabolites produced in this genus, in particular, Pilea microphylla species [8-10]. The objective of this study is to isolate and identify the chief hypoglycaemic component of Pilea elizabethae.

\section{MATERIALS AND METHODS}

\section{Materials}

Flash and gravity column chromatography were carried out using 200-425 mesh silica gel from Sigma. Thin layer chromatography (TLC) was performed on pre-coated F254 Si gel 60 glass plates of $250 \mu \mathrm{m}$ thickness. Spots were visualized under long (366 nm) and 
short ( $254 \mathrm{~nm}$ ) wave ultraviolet radiation and by derivatization with ammonium molybdate-sulfuric acid reagent and heating. All solvents used were of ACS or Optima grade obtained from Fisher Chemicals. ${ }^{1} \mathrm{H}$ and ${ }^{13} \mathrm{Cspectra}$ were obtained using a Bruker ACE $200 \mathrm{MHz}$ NMR infrared spectrophotometer was recorded using a potassium bromide disc and analyzed with a Perkin-Elmer 735B fourier transform infra-red spectrophotometer.

Sprague-Dawley strain albino rats were acclimatized to animal house conditions of $25-26{ }^{\circ} \mathrm{C}$ and a 12 hour light/dark cycle respectively. The animals were fed with laboratory diet and tap water ad libitum. Blood glucose was measured using an Accu-check Advantage glucometer and strips from Roche Diagnostics.

\section{Plant collection and extraction}

Samples of Pileaelizabethae were collected from limestone soil regions in Windsor District in St. Elizabeth, Jamaica. A fresh specimen was submitted to the University of the West Indies Herbarium for authentication and preservation. The plant samples were solar dried for about seven days. The aerial parts of the plant were milled and the finely ground material was collected in clean bags and weighed. A dried, milled plant sample weighing 450-550 g was packed into a long glass column and treated with hexane, ethyl acetate and ethanol solvents successively. Each solvent (1.5 L x $24 \mathrm{~h} \times 3$ ) was added at room temperature until the plant material was saturated and completely covered. All three solvent extracts of Pilea elizabethae were concentrated under vacuum at $\left(50-60^{\circ} \mathrm{C}\right)$ to solid (ethanol), semi-solid (ethyl acetate), and a viscous liquid (hexane) residue. The extracts were kept refrigerated until hypoglycaemic screening or further fractionation was carried out.

\section{Experimental protocol}

The bio-directed purification of the chief hypoglycaemic agents contained in Pilea elizabethae followed a sequence of steps alternating oral glucose tolerance test (OGTT) bioassay and chromatographic methods. The initial crude hexane, ethyl acetate and ethanol extracts obtained were bio-assayed using OGTT. The ethyl acetate crude extract (14.35 g) which was most hypoglycaemic in activity was flash chromatographed on silica gel using a gradient hexane-ethyl acetate solvent system of increasing polarity $(1: 0 \rightarrow 1: 0)$. The fractions obtained were grouped by their similar TLC profiles into four major groups labelled E1, E2, E3 and E4. These groups were each tested by OGTT affording a selection of extract E2 (2.45 g) for further purification (hexane-ethyl acetate $=1: 0 \rightarrow 0: 1$ ). This yielded six major groups,E2AE2F. On OGTT testing, E2D and E2E were recombined as E2G (1.86 g) and subjected to isocratic gravity column chromatography with a 50:50 hexane-chloroform mixture on silica gel. Four major fractions, E2GiE2Giv, were obtained. Hypoglycaemic activity was observed in both E2Gii $(0.61 \mathrm{~g})$ and E2Giii (0.99 g). These were both recrystallized from hexane to yield the pure hypoglycaemic product R-E2Gii (0.46 g) respectively. Elucidation of the chemical structures of R-E2Gii was determined using NMR and FT-IR spectroscopy, melting point determination and comparison with the literature. The pure isolates were then subjected to further glycaemic characterization experiments.

\section{Bioassay procedure-oral glucose tolerance test (OGTT)}

The Pilea elizabethae extracts were tested for hypoglycemic activity in Sprague-Dawley albino rats weighing 250-400 g using the oral glucose tolerance test (OGTT) method with minor modifications. The animals were subjected to an overnight fast for approximately $12 \mathrm{~h}$. The animals were then weighed and fasting blood samples were taken in duplicate from the tip of the tail vein. Immediately following the fasting blood sample, the control rats were fed orally $0.5 \mathrm{ml}$ of dimethyl sulfoxide (DMSO) or $0.5 \mathrm{ml}$ of corn oil (CO) while the test rats were fed the respective extracts dissolved in $0.5 \mathrm{ml}$ of DMSO or $0.5 \mathrm{ml}$ corn oil as required (crude EtOAc- $200 \mathrm{mg} / \mathrm{kg}$ body weight; RE2Gii at $5 \mathrm{mg} / \mathrm{kg}$ and $10 \mathrm{mg} / \mathrm{kg}$ body weight). The time of feeding was noted. Thirty minutes later a second fasting blood sample was taken (labeled 30-minute sample) and a 60-minute fasting sample was taken thirty minutes later. Then the glucose load was administered orally at $1.75 \mathrm{~g} / \mathrm{kg}$ body weight immediately following the 60-minute fasting blood sample. The time of feeding was noted. Blood glucose concentrations were then measured at thirty-minute intervals for a further two and a half $h$.

\section{Elucidation of pure compound}

Isolated hypoglycaemic compounds obtained after bio-directed purification were identified through nuclear magnetic resonance (NMR) spectroscopy and infra-red (IR) spectroscopy. Briefly, a sample of the pure isolates was dissolved in deuterated chloroform. The solution was placed in the NMR tube to a height of 3-4 cm and analyzed using TMS as an internal standard. Chemical shifts $(\delta)$ were expressed as ppm with reference to the TMS resonance. For IR spectroscopy, samples of the pure isolates were analyzed in a potassium bromide disc.

\section{RESULTS}

\section{Identification of R-E2Gii}

Bio-directed purification of Pilea elizabethae extracts yielded a hypoglycaemic principle that was coded R-E2Gii. By comparison of its NMR chemical shift values and physical properties with literature values, R-E2Gii found to be the triterpenoid oleanonic acid $\left[\mathrm{C}_{30} \mathrm{H}_{40} \mathrm{O}_{3}\right.$; $\mathrm{M}$. $\mathrm{W}=124]$. It is a pale green-white, crystalline solid at room temperature. ${ }^{13} \mathrm{C}$-NMR spectroscopic analysis of R-E2Gii gave rise to thirty carbon signals in total. The functional groups: one ketone, one carboxylic group and one double bond, were identified at the following respective chemical shifts: $\delta 216.8 ; \delta 177.7$; and $\delta 121.9$ and $\delta 143.5$ (table 1). These values arose from carbons C-3, C-28 and C-12 and C13 respectively. Further to that, the ${ }^{1} \mathrm{H}-\mathrm{NMR}$ and ${ }^{13} \mathrm{C}-\mathrm{NMR}$ DEPT 135 spectra identified 7 methyl groups characteristic of oleanane triterpenoids [11] and $10\left(\mathrm{CH}_{2}\right)$ signals. Four strong $(\mathrm{CH})$ signals at $\delta 122.3$ (C-12), 855.2 (C-5), 846.8 (C-9) and $\delta 40.9$ (C-18) were distinguished from ${ }^{13} \mathrm{C}$-NMR DEPT 90 . The remaining 8 quaternary carbon signals were only observed in the ${ }^{13} \mathrm{C}-\mathrm{NMR}$ spectrum. The ${ }^{13} \mathrm{C}-$ NMR signals obtained from analysis of R-E2Gii closely correlated with the chemical shift values for oleanonic acid given by Campos and colleagues (1991) [12] and Seo and colleagues (1975) [13].

\section{Hypoglycaemic Effect of R-E2Gii}

The isolate R-E2Gii demonstrated significant hypoglycaemic activity beginning as quickly as thirty minutes post-load. When administered intravenously, values were as low as $4.87 \pm 0.09 \mathrm{mmol} / \mathrm{l}$ thirty minutes post-load compared with $5.63 \pm 0.19 \mathrm{mmol} / \mathrm{l}$ for the control $(p<0.006)$. Thirty minutes later, a further decrease in blood glucose was observed with values of $4.82 \pm 0.07 \mathrm{mmol} / \mathrm{l}(\mathrm{p}<0.00001)$. At the 150-minute interval, the mean blood glucose level in the test group was still below that of the control although not significantly (fig. 1).

An increase in dosage up to $10 \mathrm{mg} / \mathrm{kg}$ body weight amplified the post-prandial hypoglycaemic effect of R-E2Gii (fig. 2). Delivery of the glucose load at the 60-minute interval caused blood glucose levels to be increased up to $4.96 \pm 0.09 \mathrm{mmol} / \mathrm{l}(\mathrm{p}<0.006)$ within the first thirty minutes post-load. This was followed by a sharp decline to nearly fasting levels in the 120 -minute interval $[4.20 \pm 0.14 \mathrm{mmol} / \mathrm{l}$ $(\mathrm{p}<0.000052)]$ compared to peak blood glucose levels $(5.96 \pm 0.13$ $\mathrm{mmol} / \mathrm{l}$ ) in the control. Although a slight increase followed, blood glucose levels were still far below control levels $1.5 \mathrm{~h}$ after the glucose load was administered $(p<0.000009)$. The rise continued to the end of the experiment with a post-prandial high of only $5.28 \pm 0.10 \mathrm{mmol} / \mathrm{l}$.

Oral administration of R-E2Gii at $10 \mathrm{mg} / \mathrm{kg}$ body weight showed that the compound's hypoglycaemic property was more long-lasting when administered by this route. Although the mean fasting blood glucose values were slightly lower in the test group compared with the control, statistical significant hypoglycaemia was only observed after administration of the glucose load. Fig. 3 shows that every point in the post-prandial period was notably lower than the control with the lowest point occurring at the 180 -minute interval, $4.30 \pm 0.14 \mathrm{mmol} / \mathrm{l}$ ( $p<0.003$ ) versus $4.95 \pm 0.11 \mathrm{mmol} / \mathrm{l}$ for the control.

Comparison of the hypoglycaemic effect of R-E2Gii with glibenclamide showed that the isolate was only mildly effective in reducing post-prandial hyperglycaemia. Intravenous administration of $5 \mathrm{mg} / \mathrm{kg}$ BW of R-E2Gii was only half as effective as intravenous administration of glibenclamide at the same dosage (fig. 4) and similar results were observed using $10 \mathrm{mg} / \mathrm{kg}$ (fig. 5). The chemical structure of R-E2Gii is given in fig. 6. 


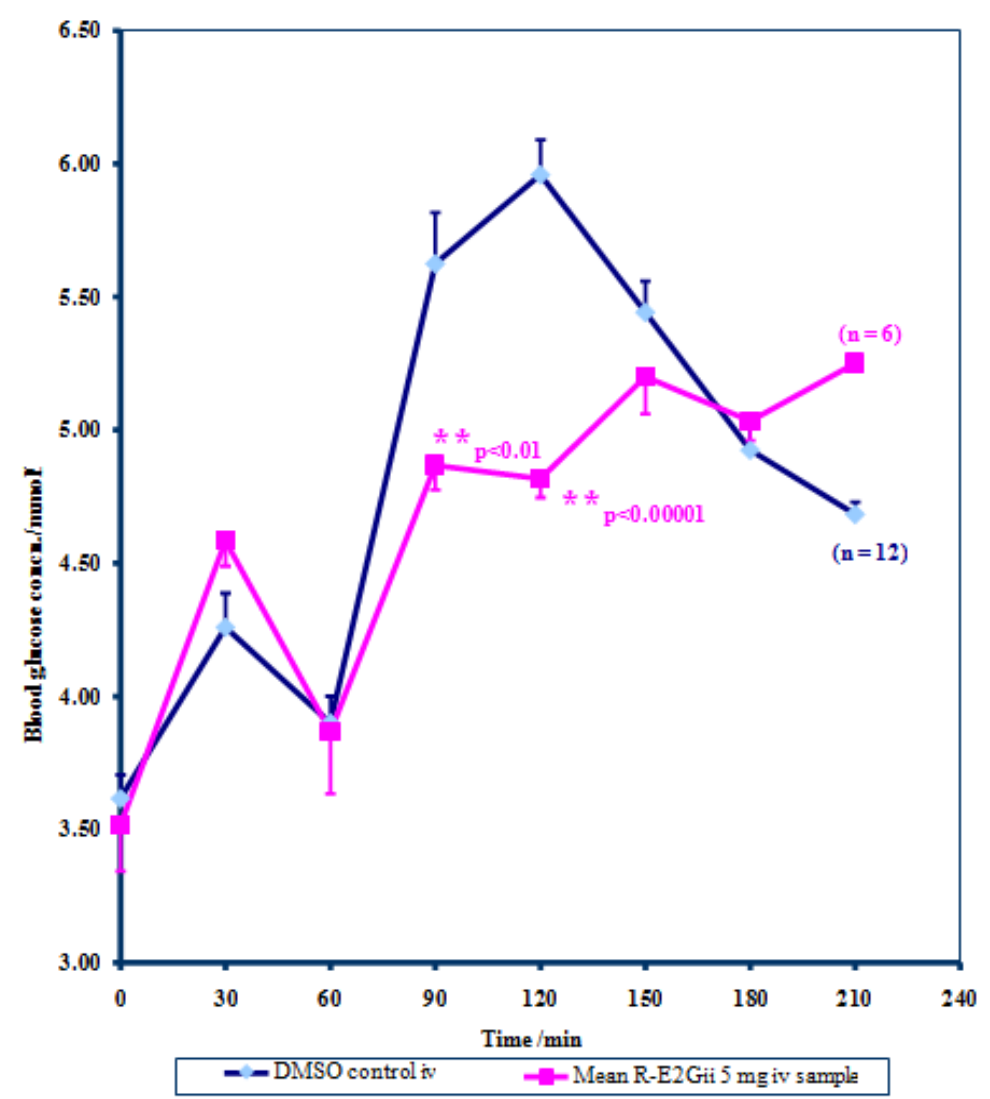

Fig. 1: Effect of R-E2Gii (i. v.) on oral glucose tolerance in rat model

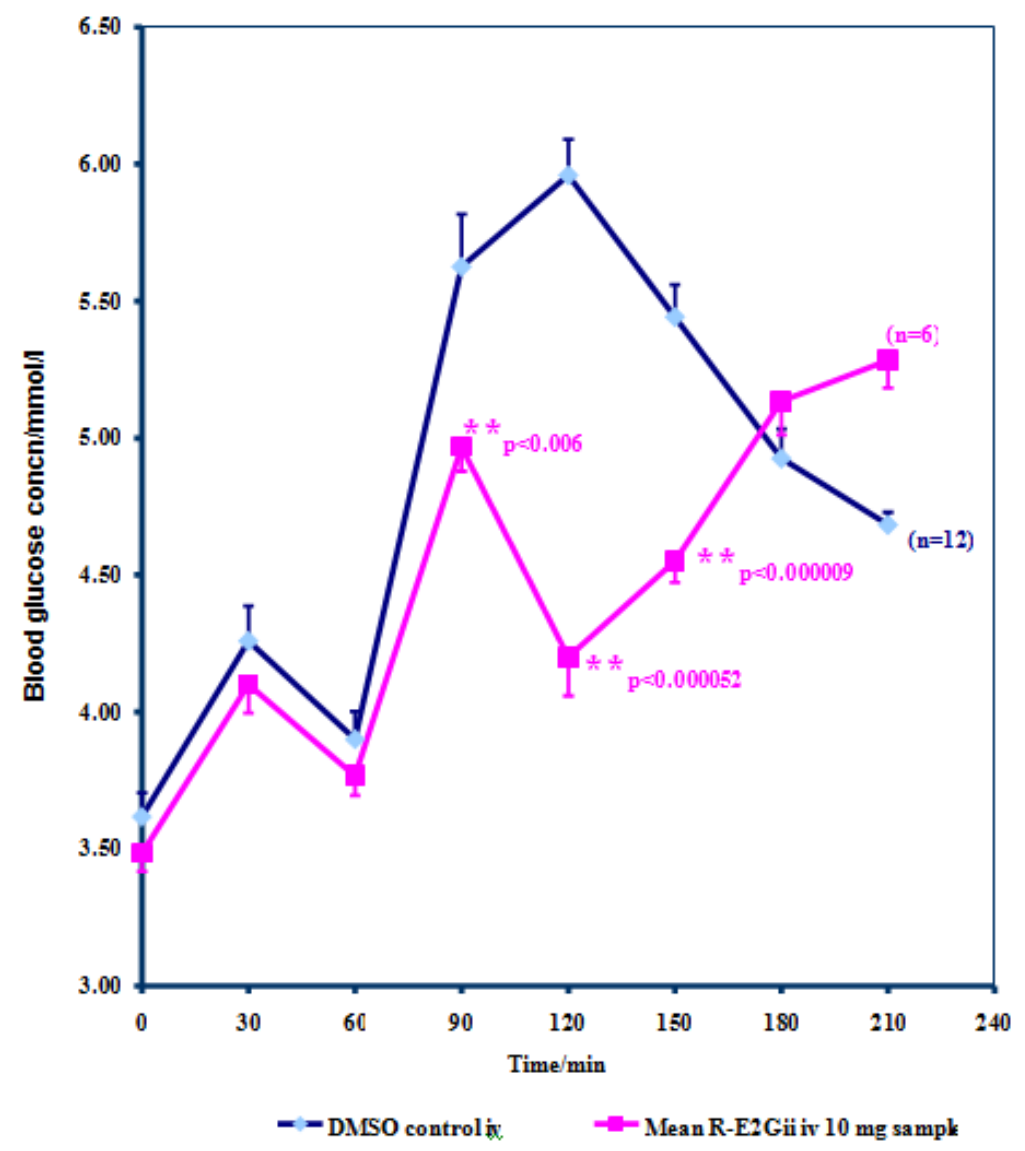

Fig. 2: Effect of R-E2Gii (i. v.) on oral glucose tolerance in rat model 


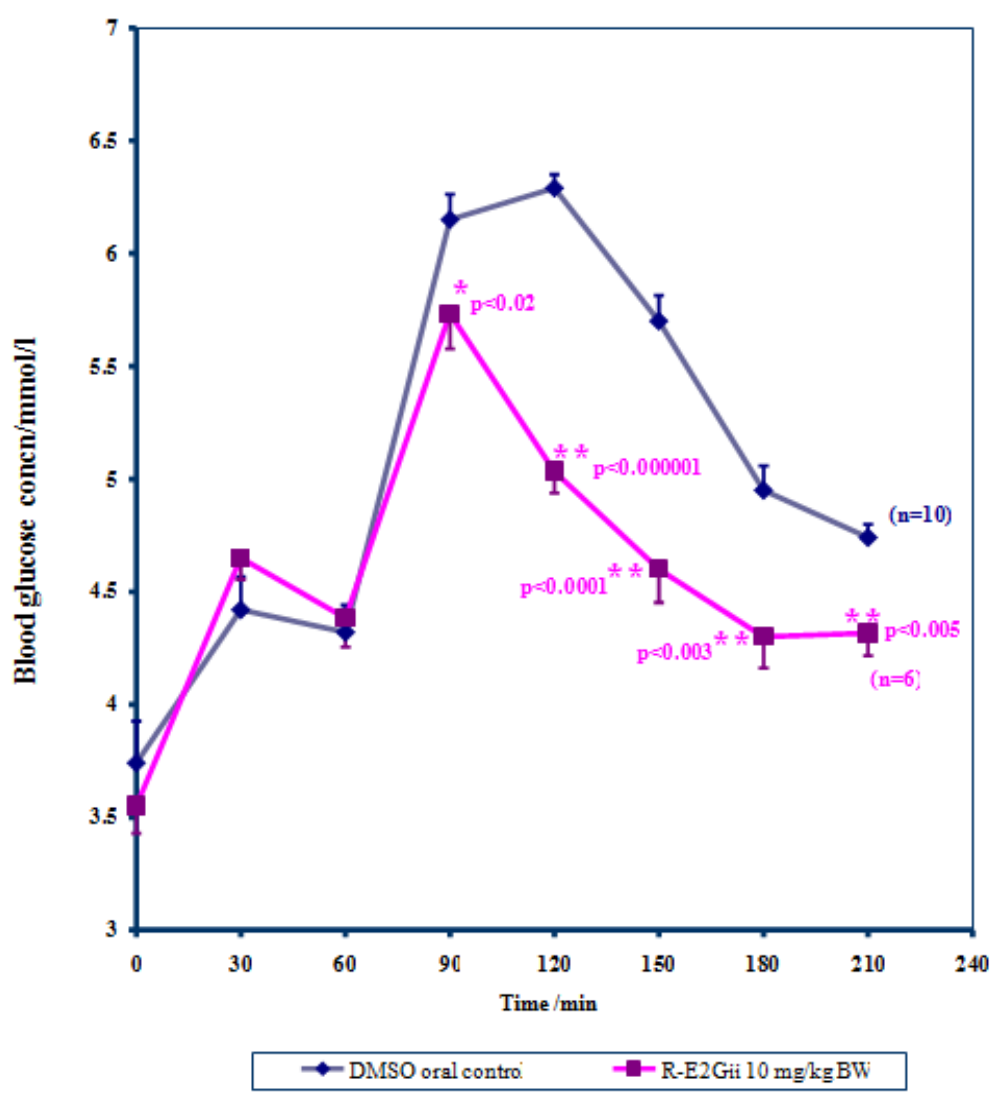

Fig. 3: Effect of R-E2Gii (i. v.) on oral glucose tolerance in rat model

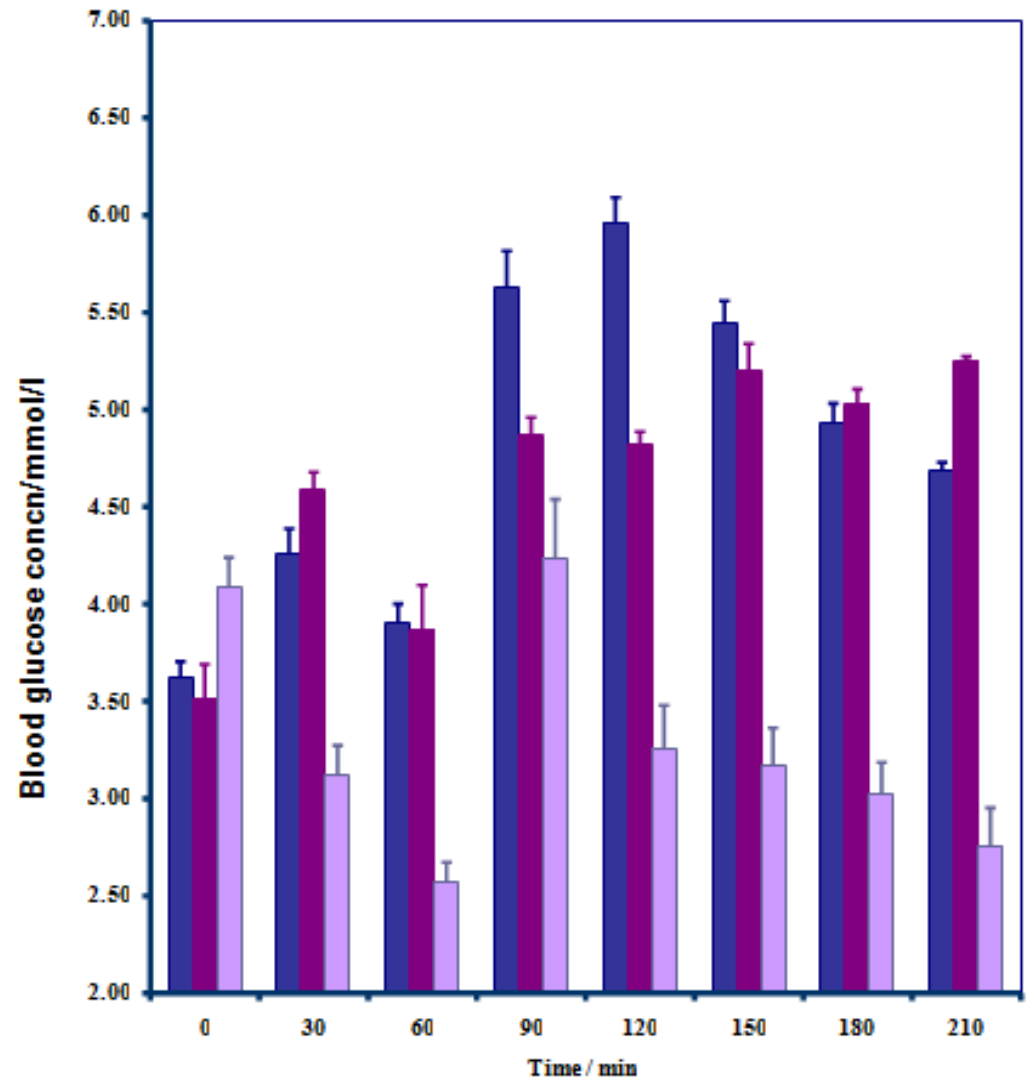

aDMSO Control aR-E2Gii $5 \mathrm{mgix} \quad \square$ Glibenclamide $5 \mathrm{mg}$ i⿵

Fig. 4: Effect of R-E2Gii (i. v.) and glibenclamide on oral glucose tolerance in rat model 


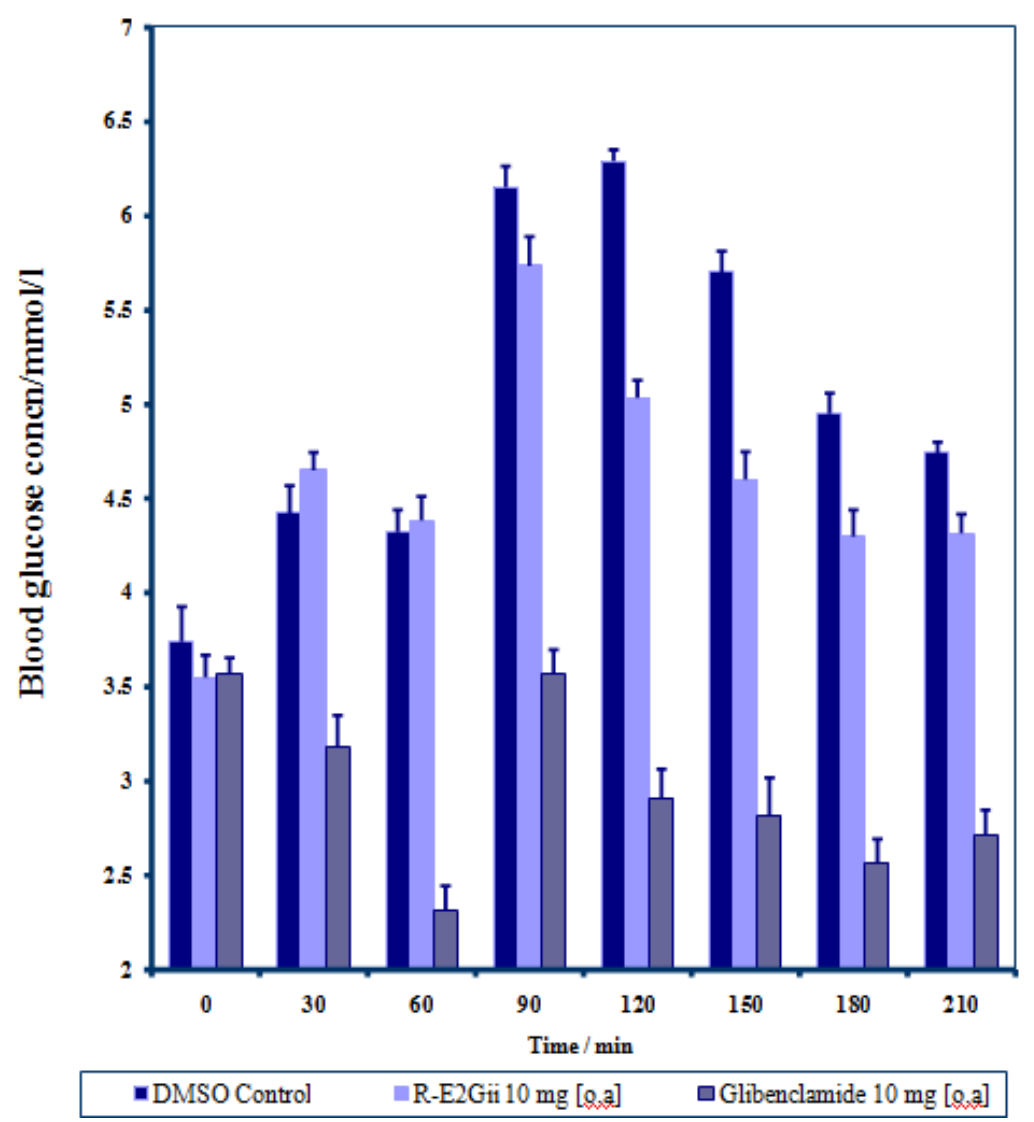

Fig. 5: Effect of R-E2Gii (i. v.) and glibenclamide on oral glucose tolerance in a rat model

Table 1: Comparison of the ${ }^{13} \mathrm{C}$-NMR chemical shifts $(\delta)$ of oleanonic acid vs. R-E2Gii

\begin{tabular}{|c|c|c|}
\hline Carbon & $\begin{array}{l}\text { Chemical shifts for R-E2Gii (Appendix two; } \\
\text { fig. } 54 \text { and 55) }\end{array}$ & $\begin{array}{l}\text { Chemical shifts for oleanonic acid from } \\
\text { Literature (Seo et al., 1990) }\end{array}$ \\
\hline 1 & 39.2 & 39.1 \\
\hline 2 & 34.1 & 34.2 \\
\hline 3 & 217.8 & 216.8 \\
\hline 4 & 47.4 & 47.3 \\
\hline 5 & 55.2 & 55.2 \\
\hline 6 & 19.5 & 19.5 \\
\hline 7 & 32.3 & 32.1 \\
\hline 8 & 39.0 & 39.1 \\
\hline 9 & 46.8 & 46.7 \\
\hline 10 & 36.7 & 36.6 \\
\hline 11 & 22.8 & 23.0 \\
\hline 12 & 122.3 & 121.9 \\
\hline 13 & 143.6 & 143.5 \\
\hline 14 & 41.6 & 41.7 \\
\hline 15 & 27.6 & 27.6 \\
\hline 16 & 23.4 & 23.5 \\
\hline 17 & 46.5 & 46.7 \\
\hline 18 & 40.9 & 41.2 \\
\hline 19 & 45.7 & 45.7 \\
\hline 20 & 30.6 & 30.5 \\
\hline 21 & 33.7 & 33.7 \\
\hline 22 & 32.1 & 32.1 \\
\hline 23 & 26.4 & 26.4 \\
\hline 24 & 21.4 & 21.3 \\
\hline 25 & 14.9 & 14.8 \\
\hline 26 & 16.9 & 16.7 \\
\hline 27 & 25.8 & 25.7 \\
\hline 28 & 184.5 & 177.7 \\
\hline 29 & 33.0 & 33.0 \\
\hline 30 & 23.5 & 23.5 \\
\hline
\end{tabular}




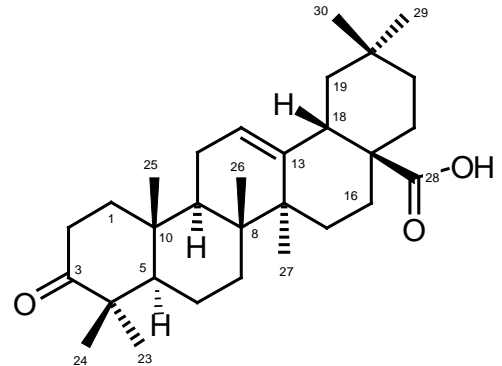

Fig. 6: Chemical structure of R-E2Gii, molecular formula: $\mathrm{C}_{30} \mathrm{H}_{40} \mathrm{O}_{3}$, molecular weight: 124 , melting point: $168^{\circ} \mathrm{C}$

\section{DISCUSSION}

Diabetes mellitus is described as a metabolic disorder that is characterized by defective secretion of insulin by the pancreatic $\beta$ cells and insulin resistance in the peripheral tissues such as muscle and adipose due to oxidative stress [14, 15]. A large number of antihyperglycaemic/anti-diabetic medicinal herbs and plants have been investigated for their therapeutic value and potential. In folklore medicine, in Jamaica, a number of plants including Pilea elizabethae have been were reputed to be useful in the treatment of diabetes mellitus. In this study, R-E2Gii (oleanonic acid) isolated from Pilea elizabethae was obtained after bio-directed purification and identified through nuclear magnetic resonance (NMR) spectroscopy and infra-red (IR) spectroscopy.

Oleanonic acid found in this study, as well as other triterpenoids such as pomonic acid and pomolic acid, the active compounds in the crude extracts of Zizyphi Fructus (ZF) and Zizyphi Semen (ZS), significantly inhibits the formation of foam cell in macrophages which was induced by acetylated low-density lipoprotein [16]. In the phytopharmacological investigation of the plant Lantana camara which has been found to have anti-filarial efficacy, oleanonic acid isolated from hexane and chloroform fractions displayed LC100 at $31.25 \mu \mathrm{g} / \mathrm{ml}$ adult Brugia malayi in vitro [17]. Oleanonic acid has also been isolated from the medicinal plant Lantana camara Linn [18-19] and has been found to inhibit nitric oxide via suppression of the inducible nitric oxide protein with macrophage viability unaffected [18]. It also had anticancer potential by its due to cytotoxic action against the human cancer cell line, A375 (malignant skin melanoma) [18]. Furthermore, oleanonic acid isolated from the roots of roots of Scrophularia ningpoensis Hemsl, a Chinese medicinal plant exhibited cytotoxicity against human cancer cell lines such as MCF7, K562, T24S and A549 [19].

We utilized the oral glucose tolerance test (OGTT) to investigate the anti-hyperglycemic properties of R-E2Gii identified as oleanonic acid. We found that R-E2Gii at a dosage of $5 \mathrm{mg} / \mathrm{kg}$ statistically significantly decreased postprandial blood glucose levels after $0.5 \mathrm{~h}$ and $1.0 \mathrm{~h}$ while $10 \mathrm{mg} / \mathrm{kg}$ exhibited the same effect after $0.5 \mathrm{~h}, 1.0 \mathrm{~h}$ and $1.5 \mathrm{~h}$ postprandially compared with control in Sprague-Dawley albino rats. This suggests that oleanonic acid has anti-hyperglycemic properties by its significant suppression of the increase in blood glucose levels following oral administration of glucose.

The antihyperglycaemic potential of oleanonic acid was further evaluated using the oral administration of R-E2Gii at $10 \mathrm{mg} / \mathrm{kg}$ body weight. This showed that a more pronounced hypoglycaemic effect with mean postprandial blood glucose values was slightly significantly lowered at all the one-half hour time points compared with control. In addition, oleanonic acid was less effective in reducing post-prandial hyperglycaemia when the intravenous administration of the compound was done at both 5 and $10 \mathrm{mg} / \mathrm{kg}$ with similar dosages of glibenclamide.

Oleanonic acid has been isolated from a number of medicinal plants such as Lantana camara LINN (family: Verbenaceae) and pharmacological investigations have shown that aqueous extracts of the leaves possess antihyperglycaemic activity [20]. In the Sunderban mangrove forest's natural environment oleanonic acid was formed due to the oxidation of oleanolic acid present in the leaves of Avicennia officinalis [21]. Oleanolic acid (3ß-hydroxy-olean12-en-28-oic acid) is a natural constituent of medicinal plants and has been found to be present in over 120 plant species [22]. There is substantial evidence in the literature of the anti-diabetic acidity of oleanolic acid. Oleanolic acid improves glucose tolerance through a multi-factorial mechanism including increasing insulin biosynthesis and secretion, as well as the promotion of beta-cell proliferation and survival [23]. Oleanolic acid also improves the sensitivity of insulin in peripheral tissues via multi-targeted mechanisms including: stimulation of insulin receptor autophosphorylation [24], inhibition of protein-tyrosine phosphatases PTP1B and TCPTP [25], activation of PI3K/Akt [26], activation of LKB1/AMPK [27], inhibition of glycogen synthase kinase-3 $\beta$ by phosphorylation [28], transactivation of peroxisome proliferator-activated receptors [29]. The mechanism of the anti-hyperglycemic activity of oleanonic acid is unknown and could include any of the above-mentioned.

\section{CONCLUSION}

Hexane-ethyl acetate extracts from Pilea elizabethae was found to possess antihyperglycaemic activity on OGTT. Bio-directed purification of the hexane-ethyl acetate extracts and using nuclear magnetic resonance (NMR) spectroscopy and infra-red (IR) spectroscopy revealed oleanonic, that may be responsible for the anti-hyperglycemic properties of this extract.

\section{ACKNOWLEDGEMENT}

Thanks to the former Chief Medical Officer for granting permission to publish the data in this paper. Special thanks to the Directors in Health Promotion and Protection Division and the Statisticians and the former Director of Policy, Planning and Development Division in the Ministry of Health, for information and support.

\section{CONFLICT OF INTERESTS}

The authors have no conflicts of interest to report

\section{REFERENCES}

1. American Diabetes Association. Diagnosis and classification of diabetes mellitus. Diabetes Care 2012;35:S64-S71.

2. Roglin G, Unwin N, Bennett PH, Mathers C, Tuomilehto J, Nag S, et al. The burden of mortality attributable to diabetes: realistic estimates for the year 2000. Diabetes Care 2000;28:2130-5.

3. Colberg SR, Sigal RJ, Fernhall B, Regensteiner JG, Blissmer BJ, Rubin RR, et al. Exercise and type 2 diabetes. Diabetes Care 2010;33:e147-e167.

4. Hu FB. Globalization of diabetes: the role of diet lifestyle and genes. Diabetes Care 2011;34:1249-57.

5. Eisenberg DM, Kessler RC, Van Rompay MI, Kaptchuk TJ, Wilkey SA, Appel S, et al. Perceptions about complementary therapies relative to conventional therapies among adults who use both: results from a national survey. Ann Int Med 2001;135:344-51.

6. Lennox PH, Henderson CL. Herbal medicine use is frequent in ambulatory surgery patients in Vancouver, Canada: L'usage de plante medicinal est frequent chez les patients de chirurgie ambulatorie à Vancouver, Canada. Can J Anesth 2003;50:21-5.

7. Craig WJ. Health-promoting properties of herbs. Am J Clin Nut 1999;70:491S-499S.

8. Paul P, Bansal P, Mudgal J, Nayak PG, Pannakal K, Priyadarsini I, et al. Antidiabetic, antihyperlipidemic, and antioxidant effects, of the flavonoid-rich fraction of Pilea microphylla (L.) in the high-fat diet, streptozotocin-induced diabetes in mice. Exp Toxicol Pathol 2012;64:651-8.

9. Modarresi CA, Ibrahim D, Fariza SS. Antioxidant, antimicrobial activity and toxicity test of Pilea microphylla. Int J Microbiol 2010;2010:826-30.

10. Prabhakar KR, Veerapur VP, Bansal P, Parihar VK, Reddy KM, Bhagath KP, et al. Antioxidant and radioprotective effect of the active fraction of Pilea microphylla (L.) ethanolic extract. Chem Biol Interact 2007;165:22-32.

11. Hui $\mathrm{W}, \mathrm{Li}$ M. Two new triterpenoids from rhodomyrtus tomentosa. Phytochemistry 1976;15:1741-3.

12. Campos AM, Oliveira FS, Iracema M, Machado L, Braz-filho R, Matos FJ. Triterpenes from Cedrela odorata. Phytochemistry 1991;30:1225-9. 
13. Seo S, Tomita Y, Tori K. Carbon-13 nmr spectra of urs-12-enes and application to structural assignments of components of Isodon japonicas hara tissue cultures. Tetrahedron Lett 1975;16:7-10.

14. Paolisso G, Giugliano D, Ceriollo A. Oxidative stress and diabetic vascular complications. Diabetes Care 1996;19:257-67.

15. Mortz E, Ceriello A. Is oxidative stress the pathogenic mechanism underlying insulin resistnance, diabetes and cardiovascular disease? The common soil hypothesis revisited. Arterioscler Thromb Vasc Biol 2004;24:816-23.

16. Fujiwara Y, Hayashida A, Tsurushima K, Nagai R, Yoshitomi M, Daiguji $\mathrm{N}$, et al. Triterpenoids isolated from Zizyphus jujuba inhibit foam cell formation in macrophages. J Agric Food Chem 2011;59:4544-52.

17. Misra N, Sharma M, Raj K, Dangi A, Srivastava S, MisraBhattacharya S. Chemical constituents and antifilarial activity of Lantana camara against human lymphatic filariid Brugia malayi and rodent filariid acanthocheilonema viteae maintained in rodent hosts. Parasitol Res 2007;100:439-48.

18. Ghosh S, Das Sarma M, Patra A, Hazra B. Anti-inflammatory and anti-cancer compounds isolated from ventilago madraspatana Gaertn, Rubia cordifolia Linn. and lantana camara Linn. J Pharm Pharmacol 2010;62:1158-66.

19. Nguyen AT, Fontaine J, Malonne H, Claeys M, Luhmer M, Duez P. A sugar ester and an iridoid glycoside from Scrophularia ningpoensis. Phytochemistry 2005;66:1186-91.

20. Begum S, Zehra SQ, Siddiqui BS. Two new pentacyclic triterpenoids from lantana camara LINN. Chem Pharm Bull (Tokyo) 2008;56:1317-20.

21. Misra S, Dutta AK, Choudhury A, Ghosh A. Oxidation of oleanolic acid of Avicennia officinalis leaves to oleanonic acid in the natural environment of Sunderban mangrove ecosystem. J Chem Ecol 1985;11:339-42.

22. Jager S, Trojan H, Kopp T, Laszczyk MN, Scheffler A. Pentacyclic triterpene distribution in various plants-rich sources for a new group of multi-potent plant extracts. Molecules 2009;14:2016-31.

23. Castellano JM, Guinda A, Delgado T, Rada M, Cayuela JA. Biochemical basis of the antidiabetic activity of oleanolic acid and related pentacyclic triterpenes. Diabetes 2013;62:1791-9.

24. Jung SH, Ha YJ, Shim EK. Insulin-mimetic and insulinsensitizing activities of a pentacyclic triterpenoid insulin receptor activator. Biochem J 2007;403:243-50.

25. Zhang YN, Zhang W, Hong D. Oleanolic acid and its derivatives: new inhibitor of protein tyrosine phosphatase $1 \mathrm{~B}$ with cellular activities. Bioorg Med Chem 2008;16:8697-705.

26. Feng J, Zhang P, Chen X, He G. PI3K and ERK/Nrf2 pathways are involved in oleanolic acid-induced heme oxygenase-1 expression in rat vascular smooth muscle cells. J Cell Biochem 2011;112:1524-31.

27. Liu J, Sun H, Duan W, Mu D, Zhang L. Maslinic acid reduces blood glucose in KK-Ay mice. Biol Pharm Bull 2007;30:2075-8.

28. Azevedo MF, Camsari C, Sa CM, Lima CF, Fernandes-Ferreira M, Pereira-Wilson C. Ursolic acid and luteolin-7-glucoside improve lipid profiles and increase liver glycogen content through glycogen synthase kinase-3. Phytother Res 2010;24 (Suppl 2):S220-S224.

29. Huang TH-W, Yang Q, Harada M. Pomegranate flower extract diminishes cardiac fibrosis in Zucker diabetic fatty rats: modulation of cardiac endothelin-1 and nuclear factor-kappaB pathways. J Cardiovasc Pharmacol 2005;46:856-62. 